example, a 99.99 per cent figure might well be called for, but for ordinary navigation purposes this would result in such a wide band as to be useless.

The statistician is accustomed to talk in terms of the standard deviation. This corresponds to the 67 per cent error, which may seem rather artificial; but there are sound theoretical grounds for preferring it. In any case, if the navigator sometimes wants to make use of one probability level and sometimes another, it is clear that the knowledge of a single percentage figure is of little value. What the navigator might find useful is a working rule enabling him to convert from one percentage to another. A table to do this is given below; it gives the factor by which the standard deviation of a single position line must be multiplied in order to get the percentage error.

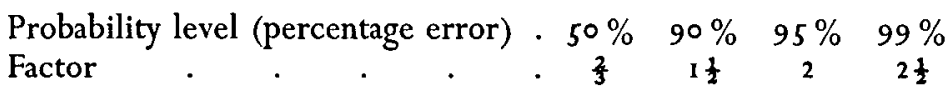

This is an easily remembered little table; thus the 95 per cent zone for a single position line is a band, the boundaries of which are two standard deviations away from the line. Using this, a good rough criterion for deciding whether a suspect position line should be ignored or not is to measure its distance from the fix obtained from the remaining position lines. If this is more than two standard deviations the position line should be thrown out. Using this criterion, and assuming a standard deviation of one nautical mile, two of Lt. Cdr. S.'s sights quoted by Commander Sharpey-Schafer in 'Some Notes on Astronomical Observations at Sea' (Fig. 1, Vol. VI, p. 365) would be disqualified. This seems reasonable.

The second question is difficult. The appropriate error circle for a fix depends not only on the number of position lines, but also on their distribution in azimuth. Without a good deal of theoretical investigation, one can only lay down the following rough-and-ready rules.

(I) For a two-line fix, with a $90^{\circ}$ angle of cut, the radius of the 50 per cent circle is $1 \cdot 2$ times the s.d. of the component position lines (alternatively $1 \cdot 75$ times the $5^{\circ}$ per cent error of the two position lines).

(2) The radius of the $5^{\circ}$ per cent (or, for that matter, any percentage figure) circle for an $n$-line fix, whose position lines are well distributed in azimuth, varies inversely as the square root of $n$. Thus a four-line fix has a radius of $\sqrt{ }(2 / 4)=0.7$ times that of a two-line fix, and an eight-line fix has a radius half that of a two-line fix. The law of diminishing returns enters with a vengeance, and improving accuracy by taking more and more position lines is a slow job. In particular, the chance of eleven sights, all with a ( 50 per cent) error of a mile, giving position lines within only three cables of the true position is very small indeed: it must have been a lucky break!

\title{
Methods of Astronomical Navigation
}

The following is an extract from a letter sent in with a series of observations made for the working party investigating the accuracy of astronomical navigation at sea.

I THINK the Institute is doing a grand job in this matter of getting to the bottom of what actually happens at sea. I give a personal 'shabash' to D. H. Sadler \& Co. for the new Abridged Nautical Almanac, and to S. M. Burton for the first- 
ever really practical manual and tables, but I am now completely 'sold' on H.D. 486 [Tables of Computed Altitude and Azimuth] and have very little to look forward to unless it be my dream of 'a small hopper, into which one throws two or more altitudes, turns a handle, and tears off a neatly printed position'. I can see no loss of caste to seamen in this. All I ever did know about a haversine, for example, was that it contained a conglomeration of figures which when conjoined with others, cosines and suchlike, led by tortuous and unseamanlike stages to a.position line on a chart. I never felt the slightest bump when crossing over to H.D. 486, where all those abominable spherical trigonometrical triangles have already been worked out by experts who, I understand, really like 'em. So ROLL OUT THAT HOPPER.

To those who say that there is a danger of us becoming 'push-button' sailors, I point out that the actual working out of a sight is merely a chore. Taking correct altitudes, choosing the bodies, and the application of results is the material matter. I would like to see the Institute produce a nice slim manual on the practice of modern navigation, including coastal, and containing all the tricks of the trade in the matter of speed, clarity and expediency, the astro part being based on H.D. 486. Something in the style of Burton's books would suit me, he being the one and only writer who caters for the practical navigator in our service. (I correct myself about the change-over. I had quite a pang leaving Burton's four-figure tables, but still hang on to them as a stand-by and for tables not included in H.D. 486.)

As Captain C. F. Halliday (Journal, Vol. VI, p. 204) purports to speak for the merchant service in general, and for well-conducted ships in particular, I feel bound to tell you that we here (working from India) most heartily disagree with most of what he says and implies. The Sun's mer. alt. is taken by the O.O.W., and is given the same weight, and no more, as any other mer. alt. The noon (ship's time) 'position' is estimated from the best available material. It serves, chiefly, to put a period to the 'day's work' for record purposes. It is not treated as a navigational fix. We think that the alt. of the Moon can be taken with far more precision than that of any other body and that therefore a more accurate P.L. can be deduced from it. We see no necessity for confining a Sun/Moon cross to apparent noon or to any other time. We do not consider any sight redundant as we navigate on a check, re-check, and check again basis. We use Marcq St. Hilaire exclusively and the position of any body with regard to the meridian or the prime vertical is not considered of any navigational value. With the Moon and Sun on opposite bearings, we give more weight to the Moon, because of less glare, less shades, \&c., and, as said before, a more accurate altitude. Using computed alt/az. tables it takes very heavy cloud to put the Moon out of view. Finally we would not say that the Moon is 'very' useful for finding the error of the compass and use it only if nothing else available in emergency. We use the Sun rising and setting because of ease in working out, but for precision prefer any low-lying star.

Last SW. monsoon, in the Chittagong-Red Sea trade, we rarely got a star fix, and in July (Colombo to Guardafui) got no star sights at all. This year, using H.D. 486 and precomputing altitudes, we rarely failed to get a good fix. We think, from our experience of these two SW. monsoons, that H.D. 486 and the new A.N.A. have brought about a near-revolution in the practice of navigation in this service. Time after time we have ended up.with an excellent fix in circumstances where the year before we would never have thought of taking our 
sextants out of the cases. We have, of course, been greatly helped by Venus and Mars in the evenings and by the Moon at all times, and I personally do not know whether these wanderers are always so conveniently placed, but have no doubt that we shall always be able to pull something out of the sky for our purpose.

We use a Rude indicator for roughing out the plan, but for real cloudy weather only the precise precomputation gives the confidence that makes one keep at it. Even in fine weather in the evenings, the skipper and myself have time to admire (?) the horizon we used to use, after we have plotted our position on the chart. Of course there has always been precomputing, but we in the body of the kirk had neither the time nor the inclination nor the talent for it. Nowadays the cadet can precompute half a dozen stars in fifteen minutes. A good A.B. could do it too.

It appears to me that it has at last been decided either (a) that we navigators of the merchant service are not to be trusted beyond simple addition in matters arithmetical, or (b) that the circumstances under which we work are such that we ought not to be pressed beyond that limit. Whatever it is I am in full agreement. ROLL OUT THE HOPPER.

S.S. Razwani.

J. M. Bratton

\title{
Radar and Collision at Sea
}

\author{
from Rear-Adniral J. A. Gauw \\ (Royal Netherlands Navy (ret.))
}

There is a fast growing realization that the Steering Rules in the Regulations for Preventing Collisions at Sea should be attuned to the use of radar. The principle underlying the suggested rules which follow is to stick to the idea of Rule 18 -that in case of risk of collision both vessels should take avoiding action. In order to make these rules practicable, a universal system has been thought out. Thus, the rules are meant to apply to vessels in sight of one another, as well as to vessels in radar-contact, or to a vessel in radar-contact with another vessel which is unaware of her presence. Secondly, there will be one and the same rule for power-driven vessels and sailing vessels.

The old complicated rule dating from the time of the hard-to-manœuvre square-rigged sailing vessels ought to be cancelled. Most sailing vessels nowadays are able to turn on the spot and, besides, most of them have an auxiliary motor ready for immediate use. Under the proposed rules, sailing yachts would no longer have the right of way over big liners, or over any other power-driven vessels. The old Rule $2 \mathrm{I}$, which has not worked so well in the past, should be cancelled. That rule has many times resulted in unpredictable manœuvres at the last moment and consequently in collisions. It served the purpose of ships having the so-called right of way. As no ship can claim the right of way any more under the rules proposed here there is no longer any need for the old Rule 21 .

Finally, it seems practicable to do away with the old Rule 24 , which has also caused many doubtful situations in the past, and to give a more restricted meaning to the term 'overtaking vessel', such as of a vessel approaching another vessel end-on from astern. Any vessel coming up with another vessel from a 